\title{
Rectal administration of diazepam in solution in the acute treatment of convulsions in infants and children
}

\author{
Anticonvulsant effect and side effects
}

FINN URSIN KNUDSEN

Department of Paediatrics, Glostrup Hospital, Denmark

SUMMARY In a prospective study 44 children, aged 6 months to 5 years, admitted to hospital with febrile convulsions or epilepsy, were treated with diazepam in solution administered rectally during 59 generalised attacks. Rectal administration of diazepam was effective in the acute treatment of convulsions in $80 \%$ of cases. In $10 \%$ the treatment failed, whereas diazepam administered intravenously had prompt effect; another $10 \%$ of the convulsions were resistant to diazepam, irrespective of the route of administration. The therapeutic effect was significantly correlated with the duration of convulsions before treatment started. Early treatment (convulsions $\leqq 15$ minutes) had effect in $96 \%$, and late treatment (convulsions $>15$ minutes) in $57 \%$ of cases. A total of 317 children admitted with febrile convulsions were treated prophylactically with diazepam administered rectally whenever the temperature was $\geqq 38 \cdot 5^{\circ} \mathrm{C}$. No case of significant respiratory depression or other serious side effects was observed. The rapid and reliable anticonvulsant effect of diazepam given rectally and the very few side effects makes this treatment a valuable alternative to IV administration in childhood.

Diazepam given intravenously is one of the best anticonvulsants available for acute use. However, during convulsions in young children IV injections are often difficult or impracticable. An alternative route, therefore, is needed. Suppositories are of limited value in emergency treatment, the therapeutic plasma concentration not being reached until after about 20 minutes (Knudsen, 1977). The anticonvulsant effect of diazepam administered IM can be unreliable because of unpredictable absorption (Dundee et al., 1974).

A solution of diazepam given rectally will be absorbed rapidly and almost completely (Agurell et al., 1975) and anticonvulsant plasma concentrations are obtained within less than $4 \pm 1$ minutes (Knudsen, 1977). However, no clinical studies are available on the value of this route of administration in the acute treatment of convulsions and on the side effects (Dulac et al., 1978).

\section{Patients and methods}

The prospective study took place between 1 October

Department of Paediatrics, Glostrup Hospital, Denmark FINN URSIN KNUDSEN, senior paediatrician
1976 and 1 October 1978, during which period 349 children with febrile convulsions and 12 with epilepsy (Table 1), aged from 6 months to 5 years, received therapeutic or prophylactic diazepam, administered rectally, while in hospital. The acute anticonvulsant effect was assessed on the basis of the therapy group and the side effects on the basis of the prophylaxis group.

Acute treatment. A total of 44 children who had convulsions on arrival in the emergency ward or who developed convulsions during admission received acute treatment with diazepam given rectally during 59 generalised attacks. The duration of the convulsion after administration of the drug was registered by means of a stop watch. If the attack had not

Table 1 Patients

\begin{tabular}{llll}
\hline Diazepam & \multicolumn{2}{l}{ No. of patients } & No. of doses \\
\cline { 2 - 3 } & $\begin{array}{l}\text { Febrile } \\
\text { convulsions }\end{array}$ & Epilepsy & \\
\hline Prophylactic & 317 & 0 & 583 \\
Therapeutic & $32(35)^{*}$ & $12(24)^{*}$ & 63 \\
Total & 349 & 12 & 646 \\
\hline
\end{tabular}

*Number of attacks. 
ceased within 5 minutes rectal treatment was repeated or the child was given diazepam intravenously. Thus, the IV route was used only when rectal administration was unsuccessful.

Prophylactic treatment. A total of 317 children admitted with febrile convulsions received prophylactic treatment with rectal diazepam when the rectal temperature was $\geqq 38 \cdot 5^{\circ} \mathrm{C}$. All of them were monitored clinically with a view to development of respiratory depression or other serious side effects. In 225 of the children the respiratory rate was recorded before each administration of diazepam and 10 minutes later-that is, at the time when the plasma concentration is at its highest (Knudsen, 1977).

Diazepam administration and dosage. We used a prepackage containing a $2.5 \mathrm{ml}$ disposable plastic syringe, a $6 \mathrm{~cm}$ long plastic tube with a blunt tip, and diazepam solution (Apozepam, ${ }^{*} 5 \mathrm{mg} / \mathrm{ml}$ diazepam, ampoules of $2 \mathrm{ml}$ ). The solution used was the undiluted ordinary IV preparation. Similar doses were given therapeutically and prophylactically. Children aged $\leqq 3$ years received $5-7 \cdot 5 \mathrm{mg}$ diazepam rectally $(0.5-0.9 \mathrm{mg} / \mathrm{kg}$ per dose), children $>3$ years were given $7 \cdot 5-10 \mathrm{mg}$ diazepam rectally $(0.6-0.8 \mathrm{mg} / \mathrm{kg}$ per dose $)$. The prophylactic treatment was repeated every 8-12 hours whenever the child had a rectal temperature of $38.5^{\circ} \mathrm{C}$ or above $(1 \cdot 0-2 \cdot 7 \mathrm{mg} / \mathrm{kg}$ per 24 hours). In the prophylaxis group, $57 \%$ of the children received one dose, $34 \%$ between 2 and 3 , and $9 \%$ of children between 4 and 6 doses over a period of 2-3 days.

Statistical methods. The P-values were calculated using the $\chi^{2}$ test or Fisher's exact test.

\section{Results}

The anticonvulsant effect of diazepam given rectally is shown in Tables 2 and 3. A total of 44 children received this treatment during 59 attacks. In 5 of these cases no effect could be expected from rectal administration, the convulsions being resistant to diazepan - that is, they did not stop even after very high doses of diazepam intravenously (2-3 mg/ $\mathrm{kg}$ per $\leqq 20$ minutes), which was given if rectal administration was unsuccessful. In $80-87 \%$ of the remaining cases $(n=54)$ rectal administration had a satisfactory anticonvulsant effect, defined as cessation of convulsions $\leqq 5$ minutes or $\leqq 10$ minutes after administration (Table 2). This group included 7 $(13 \%)$ patients with recurrences within 15 minutes

* Specially prepared by Apothekernes laboratory, Oslo, Norway.
Table 2 Anticonvulsant effect of rectal administration of diazepam

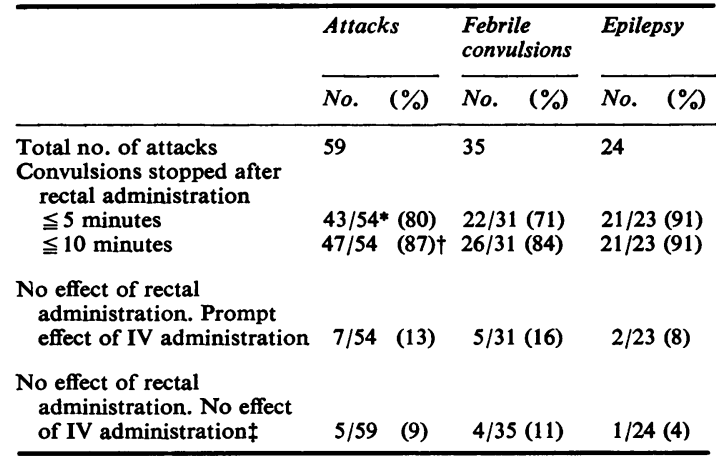

* 5 out of 59 cases were resistant to diazepam, see text and $\ddagger$.

$\dagger 7$ children had recurrences, see text.

‡Convulsions $\geqq 20$ minutes after diazepam $2-3 \mathrm{mg} / \mathrm{kg}$ per $\leqq 20$ minutes, administered intravenously.

Table 3 Anticonvulsant effect of rectal administration of diazepam as a function of the duration of the convulsions before treatment

\begin{tabular}{|c|c|c|c|c|}
\hline \multirow{3}{*}{$\begin{array}{l}\text { Duration of } \\
\text { convulsions before } \\
\text { treatment }\end{array}$} & \multicolumn{2}{|c|}{ No. of attacks } & \multirow{2}{*}{$\begin{array}{l}\text { Convulsions } \\
\text { stopped } \\
\leqq 5 \text { min after } \\
\text { diazepam }\end{array}$} & \multirow{3}{*}{$P$ value } \\
\hline & \multirow[t]{2}{*}{$\begin{array}{l}\text { Febrile } \\
\text { convulsions }\end{array}$} & \multirow[t]{2}{*}{ Epilepsy } & & \\
\hline & & & No. $(\%)$ & \\
\hline $\begin{array}{l}\leqq 15 \text { minutes } \\
>15 \text { minutes }\end{array}$ & $\begin{array}{r}7 \\
28\end{array}$ & $\begin{array}{r}17 \\
7\end{array}$ & $\begin{array}{l}23 / 24(96) \\
20 / 35(57)\end{array}$ & $<0.001$ \\
\hline Total & 35 & 24 & $43 / 59(73)$ & \\
\hline
\end{tabular}

of the first attack, the second fit stopping $\leqq 5$ minutes after administration of another dose. The therapeutic effect was significantly correlated with duration of the attack before treatment. Early treatment had effect in $96 \%$, and late treatment in $57 \%$ of cases $(\mathrm{P}<0.001)$ (Table 3$)$.

No case of clinically significant respiratory depression or other serious side effects was observed in the 317 children receiving prophylactic diazepam treatment. The respiratory rate did not change significantly $(P>0 \cdot 3)$ on the 225 children examined, even after repeated doses of diazepam $(P>0 \cdot 3)$. Sedation was common. In 2 patients who developed purulent meningitis during treatment the diagnosis was easily established, the stiffness in neck and back not being concealed by diazepam. In a third patient the possibility cannot be excluded that establishment of the diagnosis was delayed a few hours.

\section{Discussion}

Rectal administration of diazepam was effective in the acute treatment of convulsions in $80 \%$ of cases. In $10 \%$ the treatment failed, whereas diazepam given 
intravenously had prompt effect. In another $10 \%$ the convulsions were resistant to diazepam, irrespective of the route of administration (Ferngren, 1974). Early treatment was effective in $96 \%$, and late treatment in $57 \%$ of cases. Consequently, rapid intervention must be considered a prerequisite for achieving optimal anticonvulsant effect.

For ethical reasons the study did not have an untreated control group. However, the obvious correlation between treatment and cessation of convulsions indicates a significant therapeutic effect. The pronounced agreement between clinical effect and pharmacokinetic properties (Agurell et al., 1975; Knudsen, 1977) leads to the same conclusion. Lack of effect of rectal administration may be due either to poor absorption in a few cases or to convulsions which respond only to very high plasma concentrations.

No serious side effects were observed, even after repeated administration which gives rise to considerable accumulation of diazepam (Greenblatt and Shader, 1974). It remains to be clarified whether diazepam, which has a pronounced relaxing effect on muscles, may conceal stiffness in neck and back.

The rapid and reliable anticonvulsant effect and the very few side effects make the rectal route of administration a valuable supplement or alternative to IV administration in infants and children. In order of priority, according to therapeutic value, the various routes of administration of diazepam would be: IV injection, rectal administration in solution, IM injection, and suppositories.

In the prophylactic treatment of febrile convulsions (Knudsen and Vestermark, 1978) diazepam in solution offers hardly any advantages over suppositories. However, with the former, using the same medication, combined prophylactic and therapeutic control of convulsions is offered. Our experience shows that most parents with children suffering from febrile convulsions are able to treat their children at home prophylactically or in cases of recurrences. All hypnotics and psychosedatives, including benzodiazepines, have a potential respiratory-depressive effect. The treatment, which gives high plasma concentrations (Knudsen, 1977), should therefore only be given at home if the parents are carefully instructed (verbally, in writing, and by means of demonstrations), and if the child's reaction to the treatment has been studied during admission to hospital, in particular if the child is treated concurrently with phenobarbitone.

\section{References}

Agurell, S., Berlin, A., Ferngren, H., and Hellström, B. (1975). Plasma levels of diazepam after parenteral and rectal administration in children. Epilepsia, 16, 277-283.

Dulac, O., Aicardi, J., Rey, E., and Olive, G. (1978). Blood levels of diazepam after single rectal administration in infants and children. Journal of Pediatrics, 93, 1039-1041.

Dundee, J. W., Gamble, J. A. S., and Assaf, R. A. E. (1974). Letter: Plasma-diazepam levels following intramuscular injection by nurses and doctors. Lancet, 2,1461 .

Ferngren, H. G. (1974). Diazepam treatment for acute convulsions in children. Epilepsia, 15, 27-37.

Greenblatt, D. J., and Shader, R. I. (1974). Benzodiazepines in Clinical Practice. Raven Press: New York.

Knudsen, F. U. (1977). Plasma-diazepam in infants after rectal administration in solution and by suppository. Acta paediatrica Scandinavica, 66, 563-567.

Knudsen, F. U., and Vestermark, S. (1978). Prophylactic diazepam or phenobarbitone in febrile convulsions: a prospective, controlled study. Archives of Disease in Childhood, 53, 660-663.

Correspondence to Dr Finn Ursin Knudsen, Department of Paediatrics, Glostrup Hospital, DK-2600 Glostrup, Denmark.

Received 19 February 1979 